\title{
Petroleum Engineering Simulator: Um Jogo Epistêmico sobre a Indústria do Petróleo
}

\author{
Anderson Freire ${ }^{1}$, Bruno Gadelha ${ }^{2}$ \\ ${ }^{1}$ Faculdade de Tecnologia - Universidade Federal do Amazonas (UFAM) \\ CEP 69.080-900 - Manaus - AM - Brasil \\ ${ }^{2}$ Instituto de Computação - Universidade Federal do Amazonas (UFAM) \\ CEP 69.080-900 - Manaus - AM - Brasil - \\ andersonjpf97@gmail.com, brunodicomp.ufam.edu.br
}

\begin{abstract}
From prospecting to effective oil production, there is the work of numerous professionals and involves activities that require in addition to technical knowledge, management, and decision-making skills. Such skills should be developed by future oil industry professionals. Thus, this work presents an epistemic game with the purpose of presenting the concepts of the oil industry as well as developing such skills in the students, bringing them closer to the practice in the market. The game was evaluated with 34 students and as results we highlight the player's experience and the usability of the game.
\end{abstract}

Resumo. Desde a prospecção à efetiva produção de petróleo, há o trabalho de inúmeros profissionais e envolve atividades que exigem além de conhecimento técnico, habilidades gerenciais e de tomada de decisão. Tais habilidades devem ser desenvolvidas por futuros profissionais da indústria do petróleo. Assim, este trabalho apresenta um jogo epistêmico com a finalidade de apresentar os conceitos da indústria do petróleo bem como desenvolver tais habilidades nos alunos, os aproximando da prática no mercado. O jogo foi avaliado com 34 alunos e como resultados destacam-se a experiência do jogador e a usabilidade satisfatória do jogo.

\section{Introdução}

A falta de aproximação da academia com as empresas prejudica na formação dos discentes uma vez que estes desconhecem os desafios e oportunidades no campo de trabalho [RYDLEWSKI 2014]. Com isso, surge a necessidade de auxiliar a formação desses discentes por meio de métodos que sejam capazes de dar uma noção sobre o trabalho em campo. Nesse contexto, simulações e jogos tem se apresentado como recursos alternativos para complementar a formação dos futuros profissionais.

Um "jogo sério" - tradução literal do inglês "serious game", é um software ou hardware desenvolvido por meio dos princípios do design de jogos interativos, com o objetivo de transmitir um conteúdo educacional ou de treinamento ao usuário [Prensky 2003]. O termo "sério" (serious) refere-se ao fim mais educacional do que de entretenimento do jogo. Eles tem sido amplamente utilizados nas áreas de defesa, educação, exploração científica, serviços de saúde, gestão de emergência, planejamento urbano, engenharia, religião e política, de uma forma imersiva ou interativa que possam ser usufruídas da melhor forma possível. No contexto dos jogos sérios, têm-se 
os jogos epistêmicos que consistem em ambientes de aprendizagem digitais projetados para possibilitar que aprendizes, neste trabalho chamados de alunos, desenvolvam habilidades específicas de domínio sob restrições realísticas [Rupp et al. 2010]. O jogos epistêmicos estão ligados à aprendizagem de habilidades profissionais, levando os alunos a pensarem como um, contribuindo para sua preparação ao mercado de trabalho [Ribeiro and Galera 2009].

A indústria do petróleo possui uma ampla variedade de ocupações, sendo todas elas dependentes umas das outras [Thomas 2001]. Por conta disso, os acadêmicos de engenharia de petróleo possuem grande quantidade de informações interconectadas, que, muitas vezes, acabam tornando difícil o aprendizado. Nesse contexto, desenvolveu-se um jogo sério que tem por objetivo introduzir conceitos sobre a indústria do petróleo de uma forma mais dinâmica, de modo que o aluno/jogador possa ver como cada vertente da engenharia de petróleo tem sua devida participação inserida no contexto global. Utilizando os conceitos de estratégia em tempo real, é possível mostrar ao aluno/jogador profissionais de diferentes áreas da engenharia de petróleo atuando em campo e tornar mais simples o entendimento dos conceitos teóricos envolvidos, além de possibilitar a experimentação de diversas estratégias possíveis dentro de uma plataforma de petróleo.

O artigo está organizado da seguinte forma: na Seção 2 são apresentados os conceitos da indústria do petróleo trabalhados no jogo proposto e de jogos epistêmicos; a Seção 3 descreve a metologia de desenvolvimento e avaliação do jogo proposto; a Seção 4 apresenta o jogo desenvolvido de acordo com a metodologia definida; a Seção 5 apresenta os resultados e discussão sobre a avaliação do jogo com alunos de graduação do curso de Engenharia de Petróleo e Gás e, por fim, na Seção 6 são apresentadas as conclusões do trabalho.

\section{Fundamentação Teórica}

Este trabalho apresenta um jogo que visa apresentar conceitos relacionados à indústria do petróleo, principalmente no que diz respeito às atividades realizadas em campos de extração e exploração. Por se tratar de um jogo com o intuito de desenvolver as habilidades profissionais dos jogadores, o jogo é classificado como epistêmico. Assim, esses dois conceitos são apresentados a seguir: conceitos e atividades básicas da indústria do petróleo e jogos epistêmicos.

\subsection{Indústria do Petróleo}

O caminho do petróleo, desde as pesquisas para sua descoberta até sua chegada a uma refinaria, passa pelas mãos de inúmeros especialistas. São geólogos de petróleo, geoquímicos, geofísicos, engenheiros de perfuração, de completação, de reservatórios, de produção, cada um deles responsável por uma etapa específica, falando uma linguagem própria e utilizando jargões peculiares [Thomas 2001]. Além da diversidade de especialistas, também há uma diversidade de atividades a serem realizadas, sendo a prospecão; a perfuração e projeto de poços e; produção do petróleo as principais. Tais atividades estão descritas a seguir:

- Prospecção de petróleo. A descoberta de uma jazida de petróleo em uma nova área é uma tarefa que envolve um longo e dispendioso estudo e análise de dados geofísicos e geológicos das bacias sedimentares. Somente após essa análise, os 
geólogos e geofísicos decidem propor a perfuração de um poço, que é a etapa que mais exige investimentos em todo o processo de prospecção [Thomas 2001]. Ainda segundo o autor, um programa de prospecção visa fundamentalmente a dois objetivos: (i) localizar dentro de uma bacia sedimentar as situações geológicas que tenham condições para a acumulação de petróleo; e (ii) verificar qual, dentre estas situações, possui mais chance de conter petróleo. Não se pode prever, portanto, onde existe petróleo, e sim os locais mais favoráveis para sua ocorrência. A identificação de uma área favorável à acumulação de petróleo é realizada através de métodos geológicos e geofísicos, que, atuando em conjunto, conseguem indicar o local mais propício para a perfuração.

- Perfuração e Projeto de Poços de Petróleo. A perfuração de um poço de petróleo é realizada através de uma sonda. Na perfuração, as rochas são perfuradas pela ação da rotação e peso aplicados a uma broca existente na extremidade de uma coluna de perfuração, a qual consiste basicamente de comandos e tubos de perfuração. Os fragmentos da rocha são removidos continuamente através de um fluído de perfuração ou lama. O fluído é injetado por bombas para o interior da coluna de perfuração e retorna à superfície através do espaço anular formado pelas paredes do poço e a coluna. Ao atingir determinada profundidade, a coluna de perfuração é retirada do poço e uma coluna de revestimento de aço é descida no poço. O anular entre os tubos do revestimento e as paredes então é cimentado com a finalidade de isolar as rochas atravessadas, permitindo então o avanço da perfuração com segurança. Após esse processo, a coluna de perfuração é novamente descida no poço, para então finalizar a perfuração. A elaboração do projeto do poço é uma das etapas de planejamento para sua construção, na qual é realizado o detalhamento das fases de perfuração e completação. O detalhamento dessas etapas é de grande importância para a determinação do tempo e do custo do poço e, consequentemente, para a avaliação de sua viabilidade técnica e econômica [Rocha and Azevedo 2009].

- Produção de Petróleo. Ao terminar a perfuração de um poço, é necessário deixálo em condições de operar, de forma segura e econômica, durante toda a sua vida produtiva. Ao conjunto de operações destinadas a equipar o poço para produzir óleo ou gás, denomina-se completação. Quanto aos aspectos técnico e operacional, deve-se buscar otimizar a vazão de produção e tornar a completação a mais permanente possível, ou seja, aquela que minimize a necessidade de intervenções futuras para a manutenção do poço. A produção do petróleo e do gás ocorrem graças a um fenômeno chamado 'elevação', que ocorre devido à pressão do reservatório ser suficientemente elevada de modo a fazer com que os fluidos contidos nele alcancem a superfície. A elevação pode ocorrer de maneira natural, quando apenas a pressão do reservatório já é suficiente para elevar os fluidos; e de maneira artificial, quando a pressão do reservatório não é suficiente, necessitando que sejam utilizados meios artificiais para elevá-los. Ao longo da vida produtiva de um campo de petróleo ocorre, geralmente, a produção simultânea de gás, óleo e água, juntamente com impurezas. Como o interesse econômico é somente na produção de hidrocarbonetos (óleo e gás), há necessidade de efetuar a separação do óleo, do gás e da água com as impurezas em suspensão, além de também fazer o tratamento e o condicionamento dos hidrocarbonetos para que possam ser transferidos para as refinarias [Thomas 2001]. 
Essas atividades correspondem às atividades envolvidas no jogo proposto, onde o aluno/jogador precisará estar atento com relação aos profissionais envolvidos e equipamentos necessários para execução de cada atividade, além da ordem de execução de cada uma delas.

\subsection{Jogos Epistêmicos}

Jogos epistêmicos são jogos de computador em que o jogador aprende a pensar como um profissional [Shaffer 2005]. Estes jogos reproduzem situações e fornecem ferramentas para que o jogador realize atividades como: engenharia, planejamento urbano, design de moda, controladoria de tráfico aéreo, gerência de lojas, hotelaria, jardinagem, medicina, logística de transportes, direção escolar, construção civil, agronomia, direção hospitalar, veterinária, zootecnia, turismo, dentre outras atividades profissionais.

Através dos jogos epistêmicos estudantes tornam-se mais preparados para o mercado de trabalho. Além do conhecimento adquirido, os estudantes tem a experiência de tomar decisões como profissionais. No jogo, o sucesso em sua carreira ou empreendimento dependerá do seu domínio sobre atributos e variáveis distintas de cada profissão [Ribeiro and Galera 2009].

Jogos epistêmicos não têm como principal objetivo propor diversão ao jogador. Trata-se de simuladores de profissões objetivando o aprendizado de novos conceitos e formas de pensar. Os destinados para adultos podem ser paralelamente classificados como serious games. E quando trata de atividades onde o jogador assume a gerência de grandes empresas administrando fortunas, o jogo pode ser categorizado como tycoon. Outras relações podem ser feitas com time management games, ou sims games[Ribeiro and Galera 2009].

\subsection{Trabalhos Relacionados}

Durante o desenvolvimento deste trabalho, foram analisados trabalhos com propostas semelhantes às deste, com o objetivo de comparar métodos e resultados, afim de melhorar a experiência da pesquisa.

Um dos trabalhos se chama Quest for Oil, jogo criado e desenvolvido pela empresa norueguesa Maersk Oil em 2013. Trata-se de um jogo de RTS ambientado na exploração Offshore de óleo e gás. O jogo simula as atividades de prospecção geofísica e perfuração de poços utilizando cenários e animação em 3D com câmera em terceira pessoa com ponto de vista de cima. Para completar o game, os jogadores têm de testar suas habilidades analíticas, procurando por petróleo em um mapa sísmico. O jogador é testado sobre como exatamente deve posicionar seu equipamento de perfuração de alta tecnologia, sempre de olho na temperatura e pressão, antes de poder começar a extrair e produzir o petróleo encontrado. Além disso, o jogador tem que fazer, constantemente, as análises corretas, tomar decisões e utilizar o conhecimento adquirido para ter sucesso (MAERSK, 2013).

Já [Hasan and Kanesan 2018] fizeram experiências com duas turmas diferentes do primeiro ano do curso de Engenharia de Petróleo na área de Geofísica durante seis semestres, uma utilizando Aprendizado baseado em Jogos, e outra sem utilizar o Aprendizado baseado em jogos. Como resultado, os autores concluem que o Aprendizado baseado em jogos tem muito potencial para dar suporte aos alunos do curso, porém, necessita ser adotado adequadamente para maximizar os benefícios desse método. 
Este trabalho diferencia-se dos demais por não só abordar apenas as áreas de Geofísica e Perfuração, como também as áreas de Completação e Produção, proporcionando uma visão mais geral da área da indústria do petróleo.

\section{Metodologia}

Para o desenvolvimento da pesquisa, foi adotada uma metodologia iterativa e integradora criada por [Rocha et al. 2014], para apoiar o desenvolvimento de jogos sérios em específico, com a finalidade de treinar e avaliar o desempenho humano. Ela foi avaliada por especialistas em Engenharia de Software e desenvolvimento de jogos sérios, e foi utilizada para criar 20 protótipos de simulações interativas e um jogo sério completo. De forma resumida, a metodologia apresenta três processos ou etapas: Planejamento (Préprodução); Produção e Pós-produção.

O Planejamento (Pré-produção) visa a elaboração do plano inicial, a partir das necessidades de treinamento, contendo a situação do mundo real que será simulada, os procedimentos e as competências que serão treinadas.

A Produção compreende as atividades de análise, projeto, implementação e integração e testes. Durante a análise são especificados os requisitos para criar o jogo sério: incluindo dados do jogo, da simulação, e da arquitetura de suporte, e do treinamento e avaliação. Durante a atividade de projeto, os requisitos de jogo são transformados em projetos detalhados visando sua implementação. Já na atividade de implementação, tais projetos são codificados. Durante a atividade de integração e teste, os artefatos são integrados e testados pelos desenvolvedores ou equipe de testes até a conclusão do desenvolvimento.

A Pós-produção consiste em duas atividades principais: execução e avaliação. $\mathrm{Na}$ atividade de execução, o jogo foi apresentado para três pesquisadores diferentes com o intuito de melhorá-lo e verificar se o mesmo cumpria seu objetivo. Dada a característica iterativa do processo adotado, após avaliações dos pesquisadores, o jogo retornou à etapa de produção para ajustes necessários. Na atividade de avaliação, o jogo foi avaliado em um estudo empírico envolvendo alunos de graduação do curso de Engenharia de Petróleo e Gás da Universidade Federal do Amazonas. Durante o estudo, os alunos realizaram um treinamento, utilizaram o jogo e, ao final, responderam os questionários de caracterização dos participantes e o formulário MEEGA+ para avaliação de jogos educacionais [Petri et al. 2017].

\section{O Jogo Petroleum Engineering Simulator}

O Petroleum Engineering Simulator é um jogo sério, epistêmico, que tem por objetivo apresentar conceitos relacionados à indústria do petróleo e criar um ambiente de simulação onde os jogadores devem tomar decisões similares às do ambiente real de trabalho. O jogo é apresentado de acordo com as etapas de desenvolvimento descritas na metodologia, na Seção 3.

\subsection{Pré-produção}

Analisando o contexto da indústria como um todo, decidiu-se desenvolver um jogo RTS (Real-time Strategy) [Buro 2003], uma vez que esse tipo de jogo propicia um ambiente onde o jogador pode testar ideias e estratégias, desenvolvendo habilidades como tomada 
de decisão, gerenciamento de recursos e planejamento. Essas habilidades são necessárias à diversas áreas profissionais, inclusive na indústria do petróleo, onde decisões incorretas podem resultar em grandes prejuízos na indústria. Analisando a proposta do gênero RTS e combinando-o com as atividades da indústria, foi decidido que o jogo seria desenvolvido com base em jogos de gerenciamento (management games). Neste tipo de jogo, o jogador necessita gerenciar uma empresa ou companhia, neste caso, uma companhia de petróleo.

A fim de tornar o jogo desafiador e educativo, algumas variáveis tiveram que ser definidas. Por ser um jogo de gerenciamento, o jogador deve ser capaz de gerenciar os ganhos e perdas da companhia de petróleo, ou seja, a pontuação no jogo é dada pela quantidade de dinheiro que a companhia consegue lucrar. No contexto da indústria do petróleo, a forma de obter lucros para a companhia é através da venda de petróleo e gás. Para tanto, é necessário que o jogador consiga prospectar e criar poços de petróleo que alcancem a fase de produção, que por sua vez, necessitam de grande investimento. Este investimento, no jogo, corresponde à contratação de profissionais e aquisição de equipamentos para as atividades da companhia. Assim, definiu-se que o jogador ganha dinheiro vendendo petróleo e gás, e perde dinheiro ao comprar equipamentos e contratando trabalhadores necessários para o desenvolvimento do poço. O objetivo do jogador então seria alcançar a fase de produção, o que consequentemente traria lucros, compensando os gastos necessários para construir mais poços. Dessa forma, um ciclo de perdas e ganhos é gerado, e o jogador deve saber administrar a fim de não levar a companhia de petóleo à falência.

O desafio no jogo está nesse gerenciamento de lucros e gastos da companhia de petróleo. Do ponto de vista educacional, o jogador é instigado a aprender os requisitos (recursos e ordem de realização de tarefas) para completar cada atividade na obtenção de poços de petróleo produtivos. Durante todo o jogo, são apresentadas informações explicativas sobre o papel dos profissionais, funcionalidade de cada equipamento e informações sobre cada uma das atividades a serem desenvolvidas (prospeção, perfuração e produção de petróleo).

\subsection{Produção}

Para o funcionamento do jogo, foi necessário estabelecer as variáveis principais do mesmo, sendo essas: (1) itens utilizados; (2) profissionais disponíveis; (3) local de trabalho, e; (4) pontuação do jogo. Basicamente, os locais de trabalho necessitariam de itens e de trabalhadores para serem desenvolvidos, gerando assim lucro, que seria a pontuação utilizada no jogo.

A primeira tela do jogo consiste no menu inicial, onde o jogador inicia suas ações no jogo. Na opção "Contratar trabalhadores", o jogador é redirecionado à tela onde o jogo apresenta uma lista de personagens disponíveis representando diferentes profissionais para trabalhar no processo de produção de petróleo. Na opção "Ir para área de Trabalho", o jogador é redirecionado para a tela onde aparece um mapa no qual o jogador decidirá onde deve criar os poços de petróleo a serem explorados. A opção "Comprar equipamentos" apresenta ao jogador uma coleção de itens, e seus respectivos valores, a serem adquiridos para a realização da atividade de desenvolvimento dos poços. A opção "Ver Inventário Atual" exibe ao jogador quais itens já foram adquiridos e quais estão sendo utilizados no momento. Por último, na opção "Ver plantel de Trabalhadores", o jogador pode visualizar os profissionais já contratados. 
VIII Congresso Brasileiro de Informática na Educação (CBIE 2019)

Anais do XXX Simpósio Brasileiro de Informática na Educação (SBIE 2019)

A "Área de trabalho" é a opção principal do jogo onde pode-se verificar os preços atuais do Barril de óleo e do gás. Além disso, também pode ser visto o dia atual do jogo. No centro, tem-se os 120 poços disponíveis do jogo, cada um com características únicas. Ao clicar em qualquer um dos 120 poços, o jogo é redirecionado à tela de gerenciamento de poços. Nessa tela de gerenciamento de poços, é exibida uma imagem ilustrativa representando o poço do lado esquerdo. Na parte superior, têm-se as opções de interação com o poço: prospectar, perfurar, iniciar produção, instalar equipamento e alocar trabalhador. Essas duas últimas redirecionam o jogador às opções de instalação de equipamentos e alocação de trabalhadores. Abaixo dessas opções, têm-se os detalhes do poço, ou seja, suas características, como profundidade, volume de óleo e gás, entre outros. Na parte inferior, tem-se um registro dos equipamentos já instalados e dos trabalhadores já operando no poço.

A Figura 1 ilustra algumas telas do jogo. Os quadros superiores apresentam os protótipos representando o projeto de interface das telas do jogo. O quadro (A) da figura mostra o projeto do menu principal do jogo e o quadro (D) exibe o menu principal implementado no jogo. O quadro (B) ilustra o projeto da tela relativa à "Área de Trabalho" do jogo que é ilustrada no quadro (E). O quadro (C) apresenta o projeto da tela de gerenciamento do poço de petróleo, que está ilustrada no quadro (F).

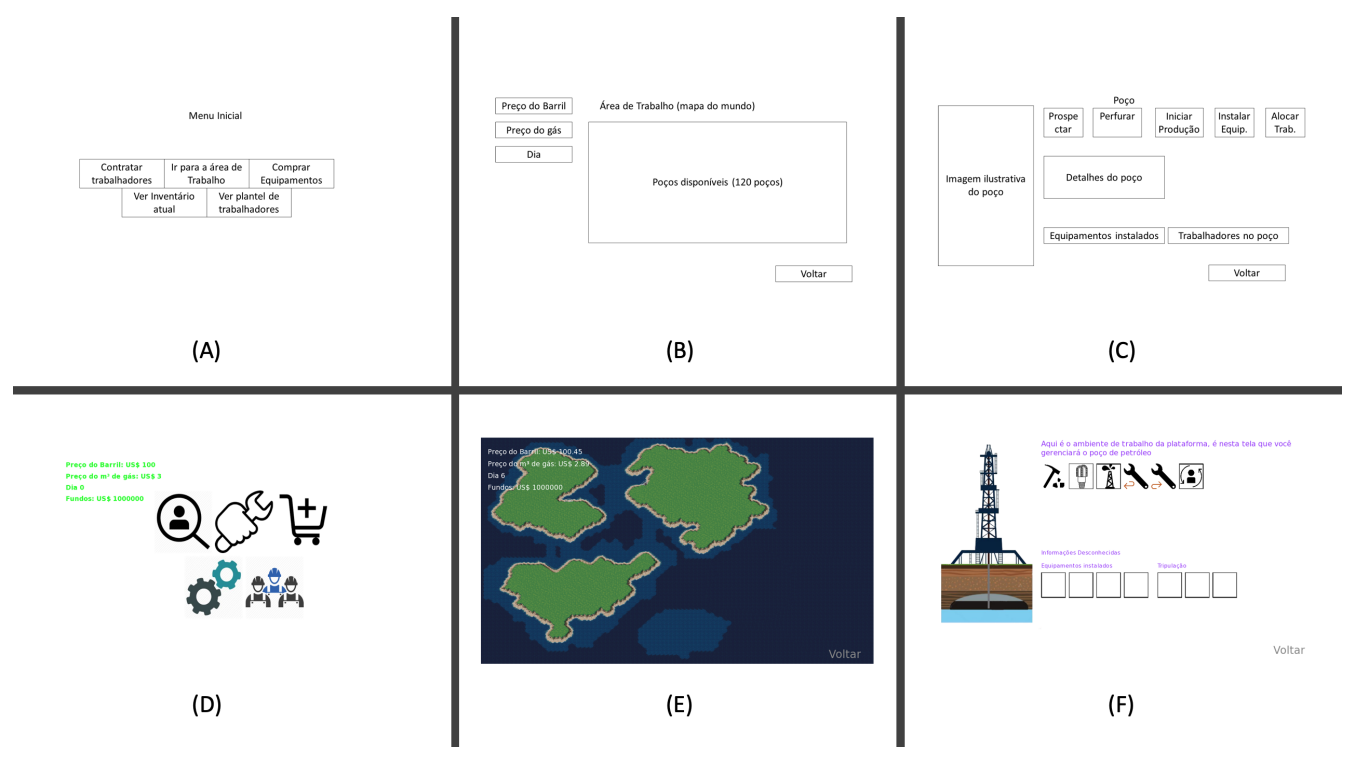

Figura 1. Protótipos e telas implementadas do PES.

O jogo foi desenvolvido em Python utilizando o Ren'py como engine de desenvolvimento que possibilita a compilação do jogo para diferentes sistemas operacionais como Windows, Linux e MacOS.

\subsection{Pós-produção}

O processo de Pós-produção do jogo envolveu duas atividades: execução e avaliação. A execução consistiu no treinamento e uso do jogo por três pesquisadores especialistas em informática na educação com o objetivo de se obter um feedback sobre o cumprimento do objetivo educacional do jogo. Com base nesse feedback, o jogo foi remodelado e iniciou- 
VIII Congresso Brasileiro de Informática na Educação (CBIE 2019)

Anais do XXX Simpósio Brasileiro de Informática na Educação (SBIE 2019)

se a atividade de avaliação que foi realizada através de um estudo empírico com 34 alunos do curso de Engenharia de Petróleo e Gás da Universidade Federal do Amazonas.

Durante o estudo, os alunos realizaram um treinamento sobre os objetivos do jogo e como manuseá-lo. Esses alunos eram todos voluntários e assinaram um termo de consentimento livre e esclarecido (TCLE). Após assinarem o TCLE, os alunos responderam a um questionário de caracterização que visando identificar o perfil dos alunos com relação ao uso de jogos digitais e a frequência desse uso. Após o preenchimento do questionário, os alunos utilizaram o jogo. Por limitações de espaço no laboratório, os alunos foram divididos em dois grupos de 17 alunos cada. O primeiro grupo consistiu nos alunos da disciplina Engenharia de Poço II, e o segundo grupo era composto dos alunos da disciplina Geofísica do Petróleo. Cada grupo teve o tempo de 15 minutos para completar a missão no jogo que era de se obter um lucro de 1,5 milhão de dólares.

Após a utilização do jogo, os alunos realizaram uma auto-avaliação através do questionário MEEGA+ [Petri et al. 2017], que continha 32 perguntas, sendo estas divididas em 2 fatores de qualidade - Usabilidade e Experiência do Jogador - e 12 dimensões - Estética, Aprendizibilidade, Operabilidade, Acessibilidade, Confiança, Desafio, Satisfação, Interação Social, Diversão, Atenção focada, Relevância e Percepção de aprendizagem. Os resultados do estudo estão descritos na seção a seguir.

\section{Resultados e Discussão}

Com relação ao perfil dos participantes, o estudo contou com 22 homens (65\%) e 12 mulheres (35\%). A faixa etária dos alunos era de 18 a 28 anos. Grande parte dos participantes (64\%) não utilizam jogos digitais com muita frequência (1 vez ou menos por mês).

O MEEGA+ foi o método de avaliação utilizado no jogo. A Figura 2 apresenta os resultados consolidados das respostas dos alunos com respeito ao fator de qualidade "Experiência do Jogador" e ilustra todas as questões relacionadas a este fator no método MEEGA+. Percebe-se que em todos os quesitos, a maioria dos alunos concordou com as afirmações apresentadas. A Figura 3 apresenta os resultados consolidados relacionados à usabilidade do jogo. De modo análogo ao fator anterior, a maioria dos alunos mostrou concordância com as afirmações apresentadas.

A análise das respostas dos alunos possibilitou a observação de pontos positivos e negativos. Como pontos positivos, os alunos declararam que o jogo, apesar de sério, foi divertido e desafiador; ficou clara a relação dos elementos do jogo com os conceitos da indústria do petróleo; percebeu-se a intenção dos alunos de usar novamente o jogo e indicá-lo aos colegas e; a aprovação, do ponto de vista dos alunos, do jogo como alternativa para motivar e apoiar a aprendizagem dos conceitos trabalhados. A usabilidade do jogo foi bem aceita pelos participantes, principalmente na questão das cores, design e fontes utilizadas.

Como aspectos negativos, vale ressaltar que a experiência para os alunos não foi tão envolvente, sendo as vezes até repetitiva e monótona, não prendendo o jogador ao jogo. Além disso, a maior crítica ao jogo foi que as regras não estavam claramente estabelecidas e não eram acessíveis no próprio jogo. 
VIII Congresso Brasileiro de Informática na Educação (CBIE 2019)

Anais do XXX Simpósio Brasileiro de Informática na Educação (SBIE 2019)

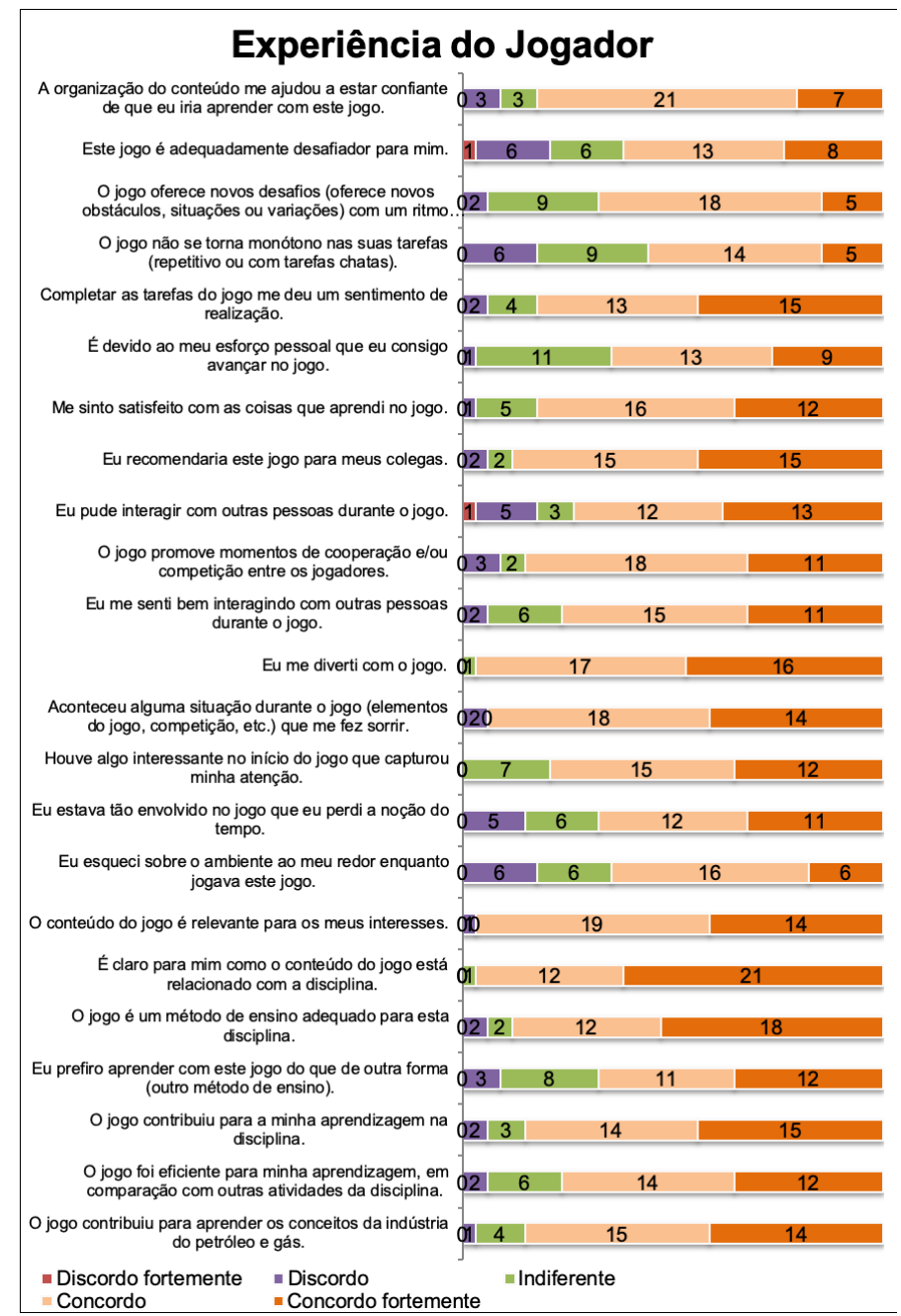

Figura 2. Experiência do Jogador.

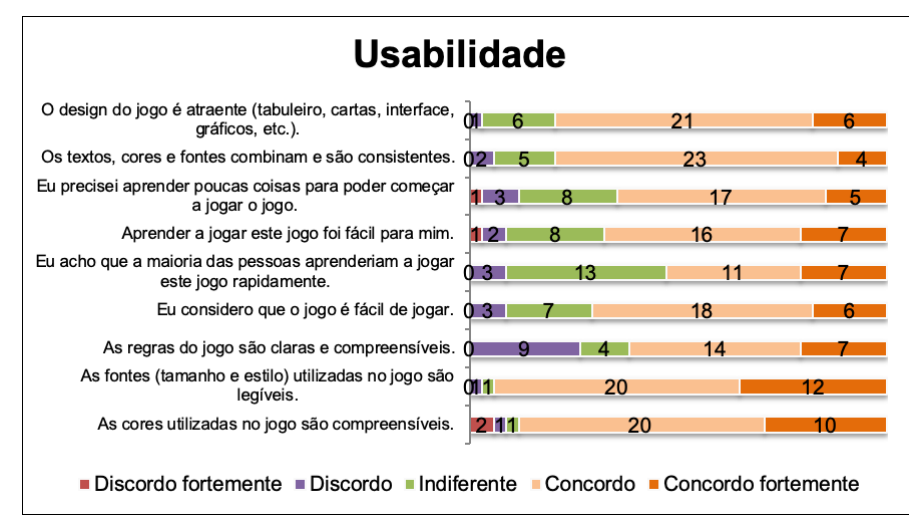

Figura 3. Usabilidade do Jogo. 
VIII Congresso Brasileiro de Informática na Educação (CBIE 2019)

Anais do XXX Simpósio Brasileiro de Informática na Educação (SBIE 2019)

\section{Conclusão}

Este artigo descreveu o processo de desenvolvimento de jogo epistêmico que visa dar suporte ao ensino da conceitos básicos da área da Engenharia de Petróleo e Gás. O trabalho propõe diminuir a principal deficiência dos graduandos que é a falta de contato com a indústria e a dificuldade de aprender, de forma prática, conceitos da engenharia. A avaliação do aplicativo deu-se por um estudo empírico, que envolveu duas turmas do curso de Engenharia de Petróleo e Gás da Universidade Federal do Amazonas. Como resultado, percebeu-se a utilidade do uso do jogo como ferramenta de suporte de aprendizagem de conceitos relativos à indústria do petróleo e a facilidade no uso do jogo.

\section{Referências}

Buro, M. (2003). Real-time strategy games: A new ai research challenge. In IJCAI, volume 2003, pages 1534-1535.

Hasan, M. L. and Kanesan, D. (2018). Evaluating game-based learning effectiveness to first year petroleum engineering students. NATIONAL ACADEMY OF MANAGERIAL STAFF OF CULTURE AND ARTS HERALD, (1):566-571.

Petri, G., von Wangenheim, C. G., and Borgatto, A. F. (2017). Evolução de um modelo de avaliação de jogos para o ensino de computação. In $25^{\circ}$ Workshop sobre Educação em Computação (WEI 2017), volume 25. SBC.

Prensky, M. (2003). Digital game-based learning. Computers in Entertainment (CIE), 1(1):21-21.

Ribeiro, R. J. and Galera, J. M. B. (2009). Jogos epistêmicos para educação.

Rocha, L. A. S. and Azevedo, C. T. d. (2009). Projetos de poços de petróleo: geopressões e assentamento de colunas de revestimentos. Interciência, Rio de Janeiro, 511.

Rocha, R. V. d. et al. (2014). Metodologia iterativa e modelos integradores para desenvolvimento de jogos sérios de treinamento e avaliação de desempenho humano.

Rupp, A. A., Gushta, M., Mislevy, R. J., and Shaffer, D. W. (2010). Evidence-centered design of epistemic games: Measurement principles for complex learning environments. The Journal of Technology, Learning and Assessment, 8(4).

RYDLEWSKI, C. (2014). Brasil sofre com qualidade de engenheiros formados no país. Acesso em, 2.

Shaffer, D. W. (2005). Epistemic games. Innovate: journal of online education, 1(6):2.

Thomas, J. E. (2001). Fundamentos de engenharia de petróleo. Interciência. 